nhân tăng huyết áp [6]

Liên quan giữa PWV và ĐTĐ, Kết quả (Bảng 6) thây PWV ở người bị ĐTĐ nhóm bệnh $(15,89$ $\pm 2,07 \mathrm{~m} / \mathrm{s})$ cao hơn nhóm chứng $(14,06 \pm 1,29$ $\mathrm{m} / \mathrm{s}$ ) có ý nghĩa. Nghiên cứu của Prenner S.B cho thấy độ cứng động mạch đóng vai trò quan trọng trong cơ chế bệnh sinh của đái tháo đường và quan trọng là rối loạn chức năng nội mô thậm chí có thể xảy ra với tình trang kháng insulin sớm và suy giảm glucose lúc đói, trước khi phát triển thành đái tháo đường. PWV là một yếu tố dự báo độc lập về tỷ lệ tử vong ở cả dân số đái tháo đường và dân số nói chung [7].

Về mối liên quan giữa độ cứng động mạch và hút thuốc lá: kết quả bảng 6 thấy: PWV ở người hút thuốc lá ở nhóm bệnh $(15,76 \pm 1,97 \mathrm{~m} / \mathrm{s})$ cao hơn nhóm chứng $(13,82 \pm 1,45 \mathrm{~m} / \mathrm{s})$ có ý nghĩa. Nghiên cứu của tác giả Yu-Jie W (2013), nghiên cứu trên $480 \mathrm{BN}$ đã chứng minh rằng hút thuốc lá làm tăng $P W V$ và khi ngừng hút thuốc trong 12 tháng làm giảm $P W V$ và tăng $A B I$, do đó cải thiện độ cứng động mạch [8].

Mối liên quan giữa thừa cân và độ cứng động mạch: kết quả bảng 6 thấy: PWV ở người thừa cân ở nhóm bệnh $(15,69 \pm 1,79 \mathrm{~m} / \mathrm{s})$ cao hơn nhóm chứng $(13,59 \pm 2,12 \mathrm{~m} / \mathrm{s})$ có ý nghĩa. Thừa cân, béo phì là một yếu tố dự báo độc lập về nguy cơ tim mạch ở cả hai giới. Nghiên cứu của Safar M.E thây những người bị béo phì làm tăng độ cứng động mạch, không phụ thuộc vào mức huyết áp, dân tộc và tuổi tác [9].

\section{KẾT LUÂNN}

Nhóm BĐMVMT có PWV tăng ( $\geq 14 \mathrm{~m} / \mathrm{s})$ chiếm tỷ lệ cao hơn nhóm chứng. Ở cùng độ tuổi, giới tính và các yếu tố nguy cơ (THA, ĐTĐ, hút thuốc lá, thừa cân) thì PWV ở nhóm bệnh đều cao hơn ở nhóm chứng có ý nghĩa thống kê với $p<0,05$.

\section{TÀI LIẸU THAM KHẢO}

1. Bộ Y tế (2020). Thực hành chẩn đoán và điều trị bễnh đông mach vành.

2. Finkler B., Eibel B., Barroso W. S., et al. (2019). Arterial Stiffness and Coronary Artery Disease. Cardiovasc Ther, 14(3): 555889.

3. Ikonomidis I., Makavos G., Lekakis J. (2015) Arterial stiffness and coronary artery disease. Current opinion in cardiology, 30(4): 422-431.

4. Nguyến Thành Trung, Hoàng Anh Tiến (2014). Nghiên cứu vận tốc sóng mạch và chỉ số huyết áp cổ chân - cánh tay ở bểnh tim thiếu máu cự bô Tạp chí Y dược học - Trường đại học Y dược Huế, 22+23: 253-261.

5. Yamashina A., Tomiyama H., Arai T., et al. (2003). Brachial-ankle pulse wave velocity as a marker of atherosclerotic vascular damage and cardiovascular risk. Hypertension Research, 26(8): 615-622.

6. Munakata M., Konno S., Miura Y., et al. (2012). Prognostic significance of the brachial-ankle pulse wave velocity in patients with essential hypertension: final results of the J-TOPP study. Hypertension Research, 35(8): 839-842.

7. Prenner S.B., Chirinos J.A. (2015). Arterial stiffness in diabetes mellitus. Atherosclerosis, 238(2): 370-379.

8. Yu-Jie W., Hui-Liang L., Bing L., et al. (2013) Impact of smoking and smoking cessation on arterial stiffness in healthy participants. Angiology, 64(4): 273-280.

9. Safar M.E., Czernichow S., Blacher J. (2006). Obesity, arterial stiffness, and cardiovascular risk. Journal of the American Society of Nephrology, 17(4 supple 2): S109-S111.

\title{
BÁO CÁO NHÂN MộT TRƯờNG HỢP CHỬA TRỨNG XÂM NHẬP Ở PHỤ NỮ TIỀN MÃN KINH VÀ HồI CỨU Y VĂN
}

\section{Lê Phong Thu', Trần Thị Kim Phượng ${ }^{1}$, Dương Hải Yến ${ }^{2}$}

\section{TÓM TẮT}

Chửa trứng xâm nhập là bênh phổ biến trong số các bệnh lý nguyên bào nuôi thai kỳ. Tần suất gặp chửa trứng xâm nhâp đứng hàng thứ 2 sau chửa trứng không xâm nhập. Chửa trứng xâm nhập phá hủy tại tử cung, xâm nhập mạch máu và có thể di căn

\footnotetext{
${ }^{1}$ Đại học Y Dược Thái Nguyên

²Bênh viện Trung ương Thái Nguyên

Chịu trách nhiệm chính: Lê Phong Thu

Email: lephongthu@tnmc.edu.vn

Ngày nhận bài: 10.9.2021

Ngày phản biên khoa hoc: 9.11 .2021

Ngày duyệt bài: 15.11.2021
}

xa. Chửa trứng xâm nhâp thường găp ở lứa tuổi sinh đẻ, hiếm găp ở tuổi tiền mãn kinh và mãn kinh. Vì vậy, chúng tôi báo cáo ca bệnh được chẩn đoán chửa trứng xâm nhập ở tuổi 55 là trường hợp hiếm gặp. Ca bệnh: Nữ, tuổi tiên mãn kinh, rong huyết kéo dài, không có tiên sử chửa trứng hay xảy thai bất thường. BHCG cao hớn bình thường. Siêu âm và giải phẩu bênh sau mổ cho kết quả: chửa trứng xâm nhập tử cung, mạch máu. Giai đoạn FIGO I với số điểm theo FIGO 2000 là 10 điểm, thuộc nhóm có yếu tố nguy cơ cao. Sau điều trị phấu thuật và hóa trị liệu vớ Methotrexat $\times 4$ chu kỳ, bênh nhân đáp ứng tốt vớ điều trị hóa chất. Kết luận: Chửa chứng xâm nhập hiếm gặp ở bệnh nhân tiền mãn kinh. Chẩn đoán dựa vào siêu âm, định lượng BHCG và kết quả mô bệnh 
học. Điều trị chủ yếu là phẫu thuật và hóa trị liệu. Bệnh đáp ứng đặc biệt tốt với hóa chất. Bệnh tiên lượng tốt vì đáp ứng với hóa chất điều trị.

Tư khóa: chứa chứng xâm nhập, B̈HCG, nguyên bào nuôi, tiền mãn kinh, mãn kinh.

\section{SUMMARY}

\section{CASE REPORT: INVASIVE MOLE IN A} PERIMENOPAUSAL WOMAN AND REVIEW OF THE LITERATURE

Background: Invasive mole is a common disease among Gestational trophoblastic diseases. The frequency of invasive mole ranks second after noninvasive mole. Invasive pregnancy destroys the uterus, invades blood vessels and metastasis to another organs. Invasive moles mostly occur in women of reproductive age, while they are extremely rare in perimenopause and postmenopause. Therefore, we report a rare case diagnosed with invasive mole at 55 years old. Case presentation: Female, perimenopausal age, prolonged bleeding, no history of mole or abnormal abortion. BHCG is higher than normal. Ultrasound and post-operative pathology showed the following results: uterus and vascular invasion. FIGO stage I with a score according to 2000 FIGO is 10 points, belonging to the group with high risk factors. After surgery and chemotherapy with Methotrexat $x 4$ cycles. The patient responded well to chemotherapy. Conclusion: Invasive pregnancy is rare in perimenopausal patients. Diagnosis is based on ultrasound, BHCG and histopathological results. Treatment is mainly surgery and chemotherapy. The disease responds particularly well to chemotherapy. The disease has a good prognosis because of its response to chemotherapy.

Keywords: Invasive mole, BHCG, Gestational trophoblastic, perimenopause, postmenopause.

\section{I. ĐẶT VẤN ĐỀ}

Chửa trứng xâm nhập là bệnh lý phổ biến trong số các bệnh lý của nguyển bào nuôi thai kỳ, sau chửa trứng không xâm nhập. Tỷ lệ gặp nhiều gấp 6-10 lần ung thư biểu mồ màng đệm. Chửa trứng xâm nhập được định nghĩa là chửa trứng có xâm nhập cơ tử cung và mạch máu. Bệnh thường có biểu hiện chảy máu âm đạo và có tăng BHCG kéo dài. Bệnh thường được chẩn đoán sau chửa trứng bán phần hoặc chửa trứng hoàn toàn. Hiếm khi được chẩn đoán bằng hình ảnh trước khi lấy bệnh phẩm nạo hút buồng tử cung. Bệnh thường di căn đến phổi, âm đạo, âm hộ, dây chằng rộng $20-40 \%$ các trường hợp. Hiếm khi di căn đến mô mềm cạnh tủy sống. Chửa trứng xâm nhập thường gặp ở phụ nữ độ tuổi sinh đẻ, đặc biệt hiếm gặp ở phụ nữ tiền mãn kinh hoặc mãn kinh ( $\geq 50$ tuổi). Tỷ lệ gặp chửa trứng xầm nhập khác nhau ở các vùng. Tỷ lệ gặp cao nhất ở Đông Nam Á và các quốc gia vùng Trung Đông, thấp nhất ở Châu Âu và Bắc Mî̀. Trong bài này, chúng tôi báo cáo về 1 trường hợp bệnh nhân chửa trứng xâm nhập ở lứa tuổi tiền mãn kinh, không có tiền sử chửa trứng nhằm cung cấp thêm cho $y$ văn về ca bệnh hiếm gặp.

\section{THÔNG TIN CA LÂM SÀNG}

Bệnh nhân Lương Thị Ch., 55 tuổi. Địa chỉ: Võ Nhai. Vào viện ngày $01 / 03 / 2021$ với lý do rong huyết kéo dài.

Tiên sử sản khoa: có kinh năm 17 tuổi, có 2 con, nạo thai 6-7 lần vì ngoài ý muốn.

Bệnh sử: Kinh nguyệt gần thời điểm bị bệnh không đều. Trước khi và̀o viện bệnh nhân khổng thấy kinh 2 tháng. Sau đó rong huyết kéo dài. Kết quả siêu âm: Hình ảnh chửa trứng, phần phụ, vòi trứng hai bên bình thường.

Kết quả xét nghiệm HCG lúc vào viện: 1.033.000 U/L (Bình thường $<5 \mathrm{U} / \mathrm{L}$ )

Chẩn đoán lâm sàng: Chửa trứng/ Bệnh nhân lớn tuổi.

Chỉ định mổ cắt tử cung toàn bộ ngày $6 / 3 / 2021$.

Giải phẫu bệnh bệnh phẩm mổ (Số B21-685) kết quả như sau:

Đại thể: Tử cung toàn bộ kèm 2 phần phụ. Kích thước tử cung: $12 \times 12 \times 15 \mathrm{~cm}$. Diện cắt có u đường kính $5 \mathrm{~cm}$. Buồng tử cung đầy các nang trứng to nhỏ không đều, có nhiều vùng chảy máu. Buồng trứng, vòi trứng 2 bên kích thước bình thường.

Vi thể: Thấy trục liên kết của các gai rau thoái hóa nước toàn bộ. Tế bào nuôi quá sản mạnh, sắp xếp lộn xộn thành đám hoặc rời rạc. Các tế bào nuôi có nhân lớn, kiềm tính, chất nhiễm sắc thô, màng nhân méo mó. Nhiều vùng các tế bào nuôi xâm nhập cơ tử cung, xâm nhập mạch máu trong cơ tử cung. Xen kẽ có vùng hoại tử chảy máu. Buồng trứng và vòi trứng khổng có hình ảnh bất thường. Kết luận: Chửa trứng xâm nhập tại buồng tử cung.

Chẩn đoán lâm sàng sau phẩu thuật: Chửa trứng xâm nhập FIGO giai đoạn I, điểm yếu tố nguy cơ: 10 (trong đó: tuổi 1 điểm, tiền sử nạo phá thai trước đó: 1 điểm, khoảng thời gian lần mang thai cuối đến khi bị bệnh: 4 điểm, định lượng BHCG trước điều trị: 4 Điểm).

Sau phẫu thuật: HCG: 1320U/L

Sau đó bệnh nhân được chuyển sang khoa u bướu điêu trị. BHCG trước điều trị hóa chất là 1566 U/L (ngày 30/3/2021). BHCG giảm dần qua các chu kỳ điêu trị hóa chất: 246,2 U/L (ngày $13 / 4 / 2021), 60,19 \mathrm{U} / \mathrm{L}$ (ngày $5 / 5 / 2021$ ), $8,36 \mathrm{U} / \mathrm{L}$ (ngày $1 / 6 / 2021) ; 6,38 \mathrm{U} / \mathrm{L}$ (ngày 15/6/2021); 2,61U/L (ngày 20/7/2021). 


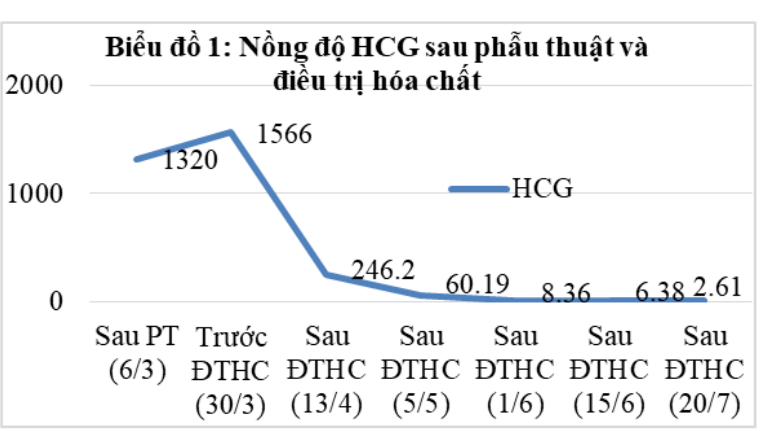

\section{BÀN LUÂN}

Các bệnh nguyên bào nuôi của rau thai bao gồm nhóm các u phát triển từ nguyên bào nuôi của rau thai sau khi trứng được thụ tinh. Tổ chức Y tế Thế giới WHO phân loại các bệnh nguyên bào nuôi trong chửa đẻ thành: chửa trứng lành tính, chửa trứng xâm nhập, ung thư biểu mô màng đệm, các u nguyên bào nuôi ở vị trí bám của rau thai, các u nguyên bào nuôi hiếm gặp và không được xếp loại. Các bệnh nguyên bào nuôi ác tính của rau thai có xu hướng xâm nhập tại chỗ và di căn xa, chúng đáp ứng tốt với hóa trị liệu. Cơ chế bệnh sinh của chửa trứng xâm nhập chưa được xác định rõ ràng. Có một số giả thuyết cho rằng bệnh nguyên bào nuôi của rau thai liên quan đến tuổi của cha mẹ, nhóm máu $\mathrm{ABO}$, tiền sử chửa trứng, tiền sử sảy thai tự nhiên, biện pháp tránh thai và các yếu tố về môi trường². Tỷ lệ gặp cao nhất ở nhóm dưới 20 tuổi và nhóm tuổi trên 40 so với nhóm từ 20-35 tuổi. Nguy cơ đặc biệt cao ở phụ nữ trên 45 tuổi. Liên quan giữa bệnh lý nguyên bào nuôi của rau thai với tuổi khác nhau giữa các nghiên cứu. Tỷ lệ mắc bênh nguyên bào nuôi của rau thai khác nhau giữa các vùng địa lý có thể do quan điểm chẩn đoán hoặc tiêu chuẩn không rõ ràng ${ }^{1}$. Tỷ lệ gặp của chửa trứng xâm nhập chiếm khoảng 15$20 \%$ các trường hợp chửa trứng hoàn toàn, tỷ lệ gặp ít hơn (1-5\%) những trường hợp chửa trứng bán phần ${ }^{1}$. Trường hợp bệnh nhân chúng tôi báo cáo có tuổi 55 , lứa tuổi có nguy cơ mắc các bệnh lý nguyên bào nuôi cao, tuy nhiên không phải đã mãn kinh như báo cáo của Ismail và cộng sự về trường hợp có cùng lứa tuổi.

Năm 1985, Tsukamoto và cộng sự đã tổng hợp báo cáo 8 trường hợp chửa trứng xâm nhập trong tổng số 20 trường hợp được chẩn đoán bệnh nguyên bào nuôi trong chửa đẻ ở phụ nữ trên 50 tuổi ${ }^{3}$. Tuy nhiên, không có trường hợp nào chửa trứng xâm nhập ở phụ nữ sau mãn kinh. Năm 2019, Martinez có báo cáo về 1 trường hợp chửa trứng xâm nhập di căn phổi và âm đạo ở phụ nữ tuổi tiền mãn kinh². Gần đây nhất, năm 2021, Ismail báo cáo một trường hợp chửa trứng xâm nhập di căn phổi ở một phụ nữ mãn kinh 55 tuổi ${ }^{4}$.

Theo Ismail, chỉ có 7 ca chửa trứng xâm nhập ở phu nữ tiền mãn kinh và mãn kinh được báo cáo trên thế giới từ năm 2003 đến 2021. Trong đó, De la Fouchardière và cộng sự báo cáo một trường hợp chửa trứng xâm nhập ở một phụ nữ được xác định mãn kinh về mặt sinh học năm $2003^{5}$. Trường hợp thứ hai được báo cáo bởi Taskin và cộng sự vào năm 2006'. Một trường hợp sau đó đã được báo cáo vào năm $2015^{7}$, ba trường hợp được báo cáo trong năm 2016 ${ }^{8,9}$ và trường hợp thứ bảy được báo cáo vào năm 2019 của Martinez Leocardio và cộng sự ${ }^{2}$. Theo các báo cáo này, chảy máu âm đạo kéo dài và tử cung to là dấu hiệu lâm sàng phổ biến của chửa trứng xâm nhập. Trường hợp bệnh nhân chúng tôi báo cáo cũng dấu hiệu rong huyết kéo dài sau chậm kinh 2 tháng.

Siêu âm tử cung phần phụ được coi là phương pháp chẩn đoán hình ảnh đầu tiên các bệnh lý chửa trứng với sự xuất hiện hình ảnh của các nang nước trong buồng tử cung. Đây cũng là phương pháp dùng để theo dõi những bệnh nhân có Beta HCG tăng cao. Việc siêu âm đầu dò qua đường âm đạo cũng giúp chẩn đoán các trường hợp chửa trứng. Chụp cắt lớp vi tính và chụp cộng hưởng từ (MRI) giúp cho việc phân giai đoạn và phát hiện các tổn thương di căn, ví dụ như di căn phổi ở môt số trường hợp ${ }^{2,4}$. Trường hợp bệnh nhân chúng tôi báo cáo có kết quả siêu âm phù hợp.

Chẩn đoán dựa vào sự tăng liên tục của Beta HCG. Beta HCG của bệnh nhân chúng tôi báo cáo trước phẫu thuật là $>10^{6} \mathrm{U} / \mathrm{L}$.

Chửa trứng xâm nhập là một khối u ác tính có tính chất phá hủy tại chỗ, xâm nhập cơ tử cung, mạch máu và các tổ chức lân cận, có tỷ lệ di căn cao (30\% tại thời điểm phát hiện ban đâu). Vị trí di căn thường gặp nhất là phổi (30\%), tiếp theo là âm đạo (30\%), gan (10\%) và ít khi di căn não, xương và vú. Do đó, chụp phổi nên được chỉ định cho tất cả các trường hợp chửa trứng xâm nhập. Ngoài ra, bệnh nhân bị di căn phổi còn có có nguy cơ cao di căn hệ thần kinh trung ương và di căn bung. Điều này cho thấy viêc chup cắt lớp vi tính ổ bụng và chụp cộng hưởng từ não trong giai đoạn tiến triển là cần thiết. Trường hợp bệnh nhẩn của chúng tôi đã được chụp $X$ Quang tim phổi kết quả không có gì bất thường. 


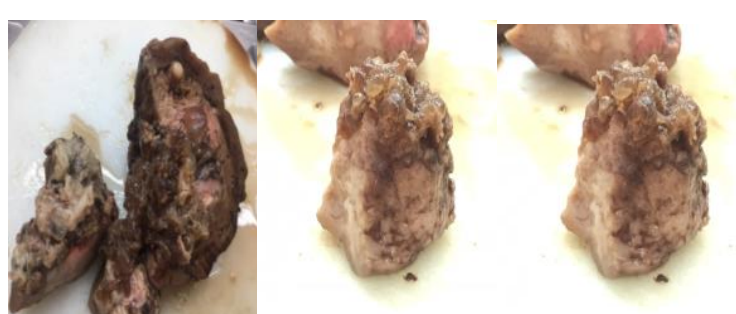

Hình 1. Hình ảnh đại thể chửa trứng xâm nhâp (B21-685)
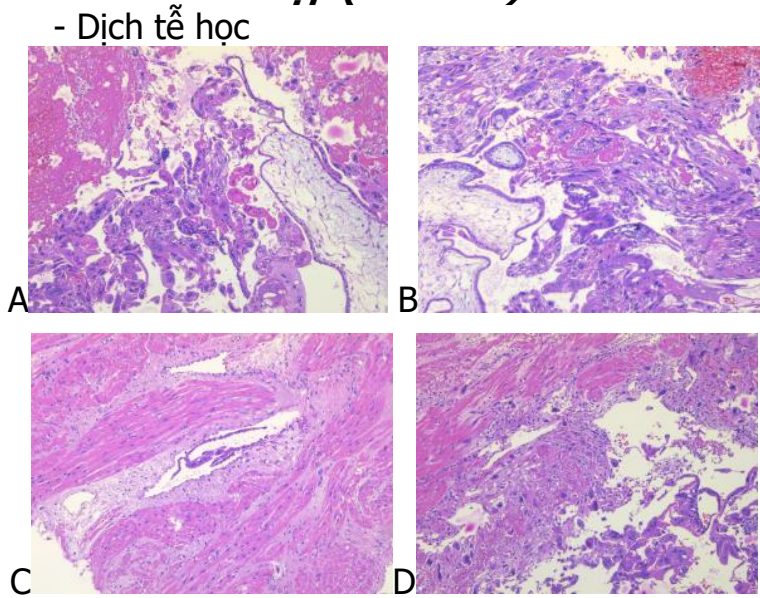

Hình 2. Hình ảnh vi thể chửa trứng xâm nhâp (B21-685)

A, B: Trục liên kết thoái hóa nước, tế bào nuôi quá sản, loạn sản, hoại tử chảy máu (HEx40); C, D: Tế bào nuôi xâm nhập cơ tử cung, mạch máu (HEx10)

Trong hầu hết các trường hợp chửa trứng xâm nhập được phát hiện dựa vào triệu chứng lâm sàng. Tuy nhiên, chẩn đoán mô bênh học đặc biệt quan trọng đối với những trường hợp không có tiền sử rõ ràng như ca bệnh của chúng tôi. Chẩn đoán xác định chửa trứng xâm nhập dựa vào mô bệnh học đôi khi cũng gặp khó khăn, cần chẩn đoán phân biệt với một số trường hợp như ung thư biểu mô màng đệm, rau cài răng lược...

Chẩn đoán phân biệt với Ung thư biểu mô màng đệm (Chorio Carcinoma) vì cả 2 đều có BHCG tắng cao. Tuy nhiên, ung thư biểu mô màng đệm không thấy hình ảnh gai rau.

Chửa trứng xâm nhập có nguy cơ cao chuyển thành ung thư biểu mô màng đệm. Đây cũng chính là chẩn đoán đầu tiên cần phân biệt với chửa trứng xâm nhập. Đặc điểm mô bệnh học của ung thư biểu mô màng đệm rõ rệt nhất là không thấy hình ảnh của gai rau, mật độ tế bào tăng cao không điển hỉnh, đơn bào nuôi và hợp bào nuôi không điển hình. Các chẩn đoán phẩn biệt khác như u ác tính hỗn hợp của ống Muller (carcinosarcoma). Có thể dễ dàng phân biệt vì chửa trứng xâm nhập không có sự phát triển 2 pha: pha biểu mô và pha mô liên kết như đối với các khối u ác tính nguồn gốc trung mô. Hình ảnh mô bệnh học trong ca bệnh của chúng tôi thấy rõ ràng hình ảnh gai rau thoái hóa nước, xung quanh là các nguyên bào nuôi quá sản mạnh xâm nhập cơ tử cung, xâm nhập mạch máu. Kết hợp với chẩn đoán hình ảnh.... Có thể chẩn đoán xác định chửa trứng xâm nhập mà không cần đến kỹ̃ thuật nhuộm hóa mô miễn dịch.

Mặc dù, chửa trứng xâm nhập có đặc tính xâm nhập, phá hủy tại chổ và có khả năng di căn cao, nhưng các tế bào ác tính này rất nhạy cảm với hóa trị liệu, được coi là phương pháp đâu tiên điều tri. Điều trị bằng phẫu thuật có thể được thực hiện trong các trường hợp cụ thể như bệnh nhân cao tuổi (tiền mãn kinh hoặc mãn kinh) hoặc chảy máu âm đạo kéo dài. Trường hợp bệnh nhẩn của chúng tôi có tuổi là 55 (tiền mã̃n kinh) chảy máu âm đạo kéo dài, nên chỉ định phẫu thuật là hợp lý, tiếp đến là hóa trị liệu. $7,9^{\circ}$

Phẩu thuật cắt tử cung toàn bộ cũng đóng một vai trò quan trọng, đặc biệt trong những trường hợp chảy máu âm đạo kéo dài điều trị nội khoa thất bại, điều này còn phòng tắc mạch máu tử cung. Phấu thuật còn được chỉ định đối với những trường hợp chửa trứng xâm nhập đơn độc tại tử cung và kháng với hóa chất điêu trị.

Phác đồ điều trị hóa chất theo giai đoạn được xây dựng bởi Liên đoàn Sản phụ khoa Quốc Tế $\left(\right.$ FIGO ${ }^{10}$. Những bệnh nhân thuộc nhóm có nguy thấp với điểm FIGO dưới 7 chỉ cần hóa trị liệu sử dụng Methotrexate. Cân nhắc phối hợp thêm Actinomycin $\mathrm{D}$ trong một số trường hợp đáp ứng kém với Methotrexate. Trường hợp nguy cơ cao có điểm FIGO trên 7, phác đồ điều trị phối hợp (EMA-CO: etoposide, methotrexate, actinomycin D, cyclophosphamide, vincristin) sau một tuần điêu trị bởi cyclophosphamide và vincristine). Trong quá trình điêu trị theo dõi nồng độ Beta $\mathrm{HCG}^{10}$. Với các bệnh nhân di căn não, cần sử dụng liều methotrexate cao hơn (kèm acid folinic). Có thể chỉ định methotrexate nội tủy cho bệnh nhân đã di căn não. Trong trường hợp của chúng tôi, điểm FIGO thuộc nhóm nguy cơ cao, giai đoạn FIGO 1 vì khối u xâm nhập khu trú ở tử cung, chưa có di căn. Số điểm là 10 (Tuổi trên 40: 1 điểm, tiền sử nạo phá thai: 1 điểm, Kích thước u: 2 điểm, nồng độ HCG trước điều trị $>10^{6} \mathrm{U} / \mathrm{L}$ : 4 điểm). Tuy nhiên, bệnh nhân đã được mổ cắt tử cung toàn bộ, nên hóa trị liêu bằng Methotrexate là phù hợp. Tuy nhiên, vẩn cần thận trọng theo dõi sát bệnh nhân trong quá 
trình điều trị.

Đối với xạ trị, việc điều trị hạn chế ngoại trừ những trường hợp chửa trứng xâm nhập có di căn não, mặc dù hiệu quả của xạ trị so với điều trị bằng Methotrexate còn nhiêu tranh cãi.

Trường hợp bệnh nhân của chúng tôi được phẫu thuật trước, sau phẫu thuật BHCG giảm mạnh (Từ 1033000U/L xuống còn 1320U/L). Sau điểu trị hóa chất 4 chu kỳ với Methotrexat, BHCG đã giảm dần về mức bình thường $<5 \mathrm{U} / \mathrm{L}$ (Biểu đồ 1 ). Kết quả cho thấy bệnh nhân đáp ứng tốt với điều trị hóa chất.

\section{KẾT LUÂ̂N}

Chửa trứng xâm nhập là bệnh lý của nguyên bào nuôi hiếm gặp ở tuổi tiền mãn kinh và mãn kinh, xâm nhập và phá hủy tại tử cung và có thể di căn xa. Bênh có tiên lượng tốt do đáp ứng tốt với điều trị hóa chất. Ca bệnh chúng tôi báo cáo là chửa trứng xâm nhập ở tuổi 55 , chưa có di căn. Sau phẫu thuật và điều trị hóa chất cho đáp ứng tốt, BHCG giảm dần về mức bình thường. Tuy nhiên, bệnh nhân vẫn cần được theo dõi định kỳ.

\section{TÀI LIÊU THAM KHẢO}

1. Altieri A, Franceschi S, Ferlay J, Smith J, La Vecchia C. Epidemiology and aetiology of gestational trophoblastic diseases. The Lancet. Oncology. Nov 2003;4(11):670-678.

2. Martinez Leocadio C, Garcia Villayzan J, Garcia-Foncillas Lopez J, Idrovo F, Plaza Arranz J, Albi Gonzalez M. Invasive mole in a perimenopausal woman with lung and vaginal metastases: A case report. Clinical case reports. Dec 2019;7(12):2300-2305.
3. Tsukamoto $\mathbf{N}$, Iwasaka $\mathbf{T}$, Kashimura $\mathbf{Y}$, Uchino $\mathbf{H}$, Kashimura $M$, Matsuyama $\mathrm{T}^{\prime}$. Gestational trophoblastic disease in women aged 50 or more. Gynecologic oncology. Jan 1985;20(1):53-61.

4. Ismail S, Mikhael $K$, Salloum N, Alshehabi $Z$. An invasive mole with pulmonary metastases in a 55-year-old postmenopausal Syrian woman: a case report and review of the literature. Journal of medical case reports. Jan 18 2021;15(1):13.

5. de la Fouchardiere A, Cassignol A, Benkiran L, Rudigoz RC, Gougeon A, DevouassouxShisheboran M. [Invasive hydatiform mole in a postmenopausal woman]. Annales de pathologie. Oct 2003;23(5):443-446.

6. Taskin S, Cengiz B, Ortac F. Invasive mole in a postmenopausal woman. International journal of gynaecology and obstetrics: the official organ of the International Federation of Gynaecology and Obstetrics. May 2006;93(2):156-157.

7. von Welser SF, Grube M, Ortmann O. Invasive mole in a perimenopausal woman: a case report and systematic review. Archives of gynecology and obstetrics. Dec 2015;292(6):1193-1199.

8. Akyol A, Simsek M, Ucer 0 . Giant invasive mole presenting as a cause of abdominopelvic mass in a perimenopausal woman: An unusual presentation of a rare pathology. Obstetrics \& gynecology science. Nov 2016;59(6):548-553.

9. Nakashima A, Miyoshi A, Miyatake $T$, Kazuhide 0, Takeshi Y. Perimenopausal invasive hyadatidiform mole treated by total abdominal hysterectomy followed by chemotherapy. Journal of surgical case reports. Sep 20 2016;2016(9).

10. Ngan HYS, Seckl MJ, Berkowitz RS, et al. Update on the diagnosis and management of gestational trophoblastic disease. International journal of gynaecology and obstetrics: the official organ of the International Federation of Gynaecology and Obstetrics. Oct 2018;143 Suppl 2:79-85.

\section{NGHIÊN CỨU TÌNH HÌNH BÊNH LÝ VIÊM TAI Ứ DICH LỨA TUỔI MẪU GIÁO NHÀ TRẺ TẠI XÃ QUỐC TUẤN HUYỆN AN DƯƠNG HẢI PHÒNG}

\section{TÓM TẮT}

Mục tiêu: Mô tả tình trạng bệnh lý viêm tai ứ dịch của trẻ em lứa tuổi mẫu giáo, nhà trẻ và tìm một số yếu tố liên quan đến bệnh lý viêm tai ứ dịch ở trẻ em. Đối tượng và phương pháp: nghiên cứu mô tả cắt ngang trên 476 trẻ độ tuổi mẫu giáo, nhà trẻ tại xã Quốc Tuấn, Huyện An Dương, Hải Phòng. Kết quả:

*Đại học Y Dược Hải Phòng

Chịu trách nhiệm chính: Ta Hùng Sơn

Email: dr.hungson@gmail.com

Ngày nhận bài: 17.9.2021

Ngày phản biện khoa họ: 15.11.2021

Ngày duyệt bài: 24.11.2021
Tạ Hùng Sơn*

viêm tai ứ dịch chiếm tỉ lệ $4,2 \%$ số trẻ, bệnh gặp nhiều hơn ở giới, tuổi dưới 3 tuổi, số người trong gia đình nhiều hơn 4 , tiền sử sinh nhe cân dưới $2,8 \mathrm{~kg}$, tân suất viêm mũi họng lớn (<2 tháng/lần); trẻ bị V.A Amiđan quá phát. Chưa thấy mối tương quan về thứ tự sinh, tiên sử nuôi dưỡng bằng sữa mè, tiên sử bệnh dị ứng với nguy cơ mắc bệnh. Kết luần: Viêm tai ứ dịch là một bệnh thường gặp ở trẻ em lứa tuổi nhà trẻ mấu giáo, yếu tố nguy cơ thường gặp là giới nam, tiền sử sinh nhe cân, tuổi nhỏ, mât độ người cùng chung sống đông, thường xuyên bị tái phát viêm mũi họng và mắc các bệnh lý V.A - Amiđan quá phát.

Từ khóa: viêm tai ứ dịch, yếu tố nguy cơ, trẻ em

\section{SUMMARY}

PREVALENCE AND RISK FACTORS OF 